Portland State University

PDXScholar

1981

\title{
A genetic and physiological study of an arsenite resistant, uncoupled mutant of Escherichia coli
}

Daniel Gordon Smiley

Portland State University

Follow this and additional works at: https://pdxscholar.library.pdx.edu/open_access_etds

Part of the Biology Commons, and the Microbial Physiology Commons

Let us know how access to this document benefits you.

\section{Recommended Citation}

Smiley, Daniel Gordon, "A genetic and physiological study of an arsenite resistant, uncoupled mutant of Escherichia coli" (1981). Dissertations and Theses. Paper 3132.

https://doi.org/10.15760/etd.3124

This Thesis is brought to you for free and open access. It has been accepted for inclusion in Dissertations and Theses by an authorized administrator of PDXScholar. Please contact us if we can make this document more accessible: pdxscholar@pdx.edu. 
AN ABSTRACT OF THE THESIS OF Daniel Gordon Smiley for the Master of Science in Biology presented July 15, 1981.

Title: A Genetic and Physiological Study of an Arsenite Resistant, Uncoupled Mutant of Escherichia coli.

APPROVED BY MEMBERS OF THE THESIS COMMITTEE:

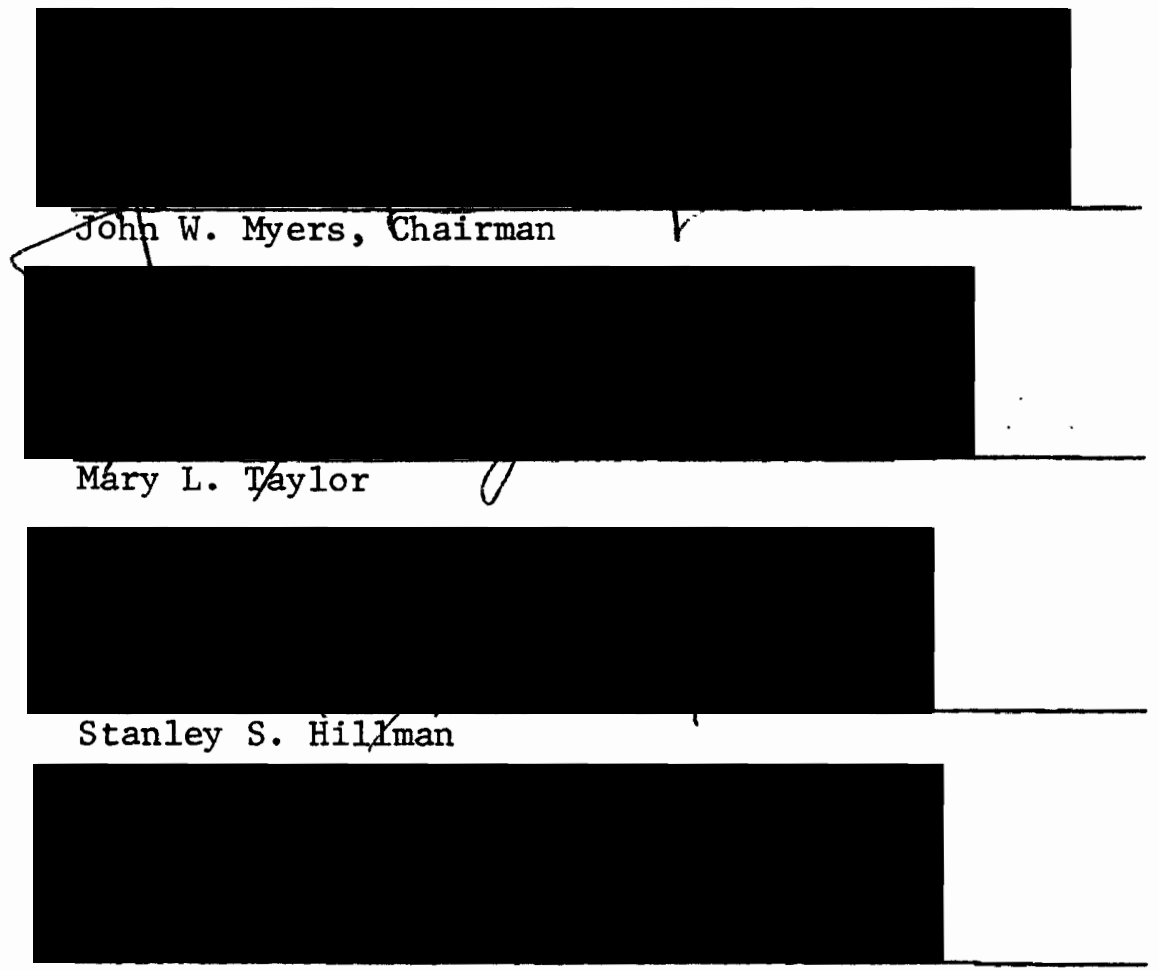

Dennis W. Barnum

Chromosomally determined arsenate resistance in Escherichia coli is well characterized. Little, however, is known about chromosomally determined arsenite resistance in E. coli. Accordingly, spontaneous arsenite resistant mutants were selected in a plasmid free strain of 
E. coli. One mutant strain was analyzed in detail, genetically and physiologically. The mutation confering arsenite resistance was shown to be a single gene mutation. Genetic mapping studies using conjugation and transduction showed that the mutation was closely linked to the $\underline{\text { ilv }}$ region of the $\underline{\mathrm{E}}$. coli map.

Physiological studies of this mutant showed that it shared characteristics common to those of mutants of $\underline{\mathrm{E}}$. coli defective in the membrane bound adenosine triphosphase (ATPase). Such cells are unable to generate ATP by oxidative phosphorylation, the major mechanism by which aerobic organisms obtain energy. As a result, these cells exhibit an inability to grow on non-fermentable carbon sources, a heightened sensitivity to streptomycin, lowered growth yields when grown aerobically in limiting concentrations of glucose, and an inability to grow anaerobically on glucose.

The arsenite resistance and the characteristics associated with a defective ATPase were shown to be the result of the same mutation. The arsenite resistance mapped in or near the operon coding for the subunits of the membrane bound ATPase. This operon is referred to as the unc operon, and is at map position 83.4 on the $\underline{E}$. coli map, 0.7 units from the ilv locus, which maps at 84.1 units.

To gain an insight into the mechanism of arsenite toxicity in $\underline{E}$. coli, ATP levels in the wild type strain and the arsenite resistant, uncoupled mutant were compared after treatment of the cells with arsenite. The effect of arsenite was to rapidly lower ATP levels in the wild type strain, whereas in the mutant strain, the levels of ATP, although lower to begin with, remained constant. 
This work provides evidence that the effects of arsenite on $\underline{E}$. coli cells is bacteriostatic rather than bacteriocidal. Arsenite inhibition of growth was shown to be reversible.

The implication that the ATPase is a target for arsenite toxicity is discussed. 
A Genetic and Physiological Study of an Arsenite Resistant, Uncoupled Mutant of

Escherichia coli

by

Daniel Gordon Smiley

A thesis submitted in partial fulfillment of the requirements for the degree of

Master of Science

in

Biology

Portland State University

1981 
TO THE OFFICE OF GRADUATE STUDIES AND RESEARCH:

The members of the Committee approve the thesis of Daniel Gordon Smiley presented JuIy 15, 1981.
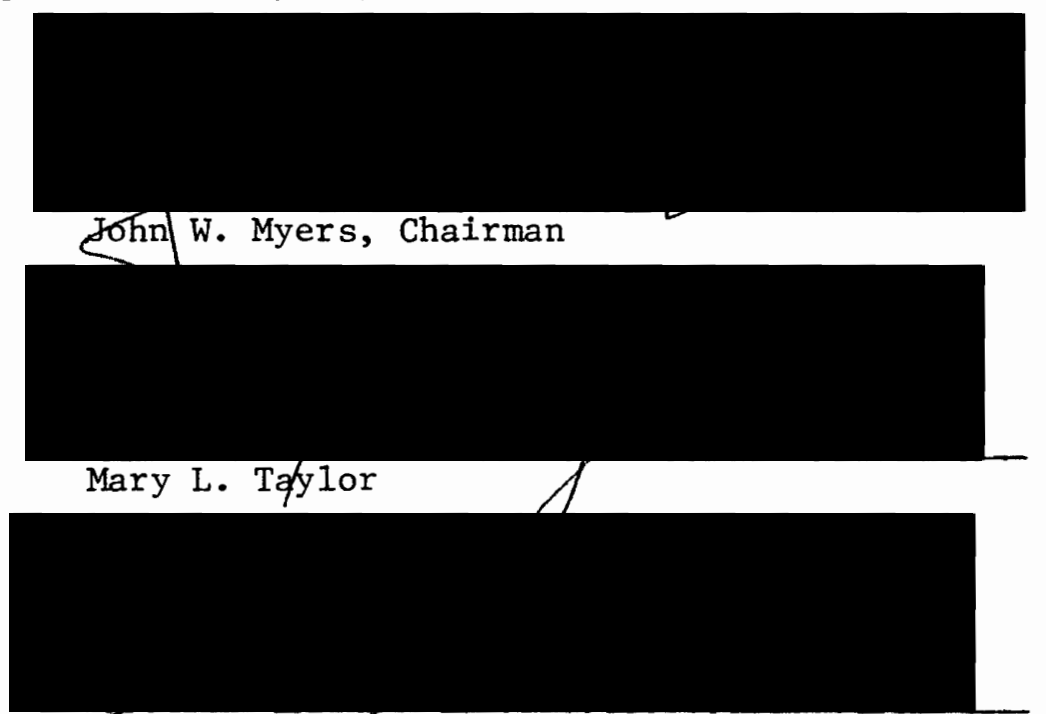

Stanley S. Hillman

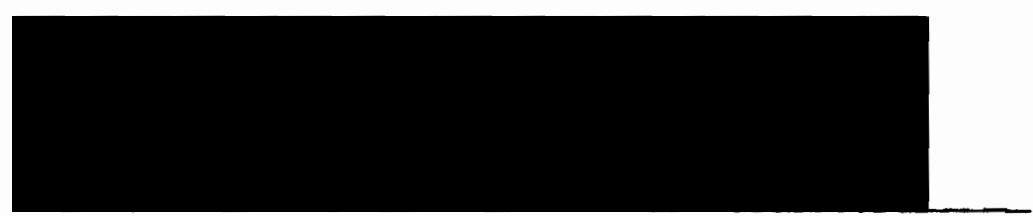

Dennis W. Barnum

APPROVED:

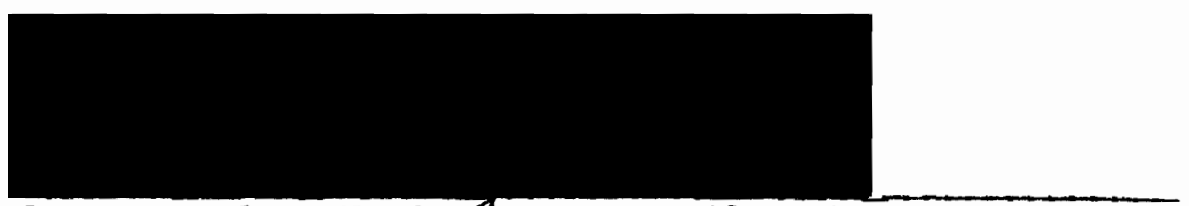

Herman Taylor, Head, Department of Biology

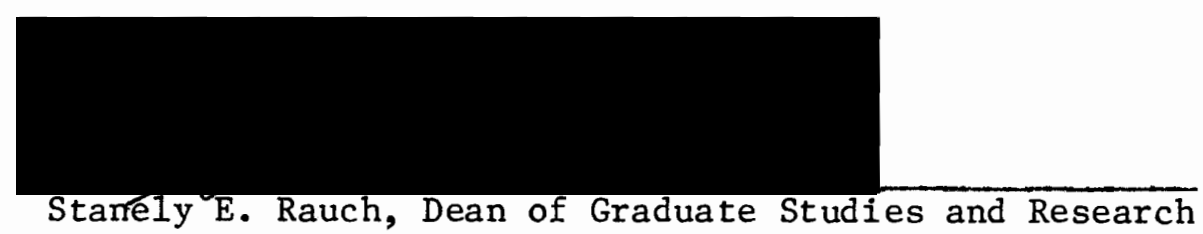




\section{ACKNOWLEDGEMENTS}

I wish to express my deepest thanks to Jack Myers who has been an integral part of this entire project. He has helped me greatly to develop as a person as well as a scientist.

I also wish to thank Mary Taylor and the other members of my committee for their helpful consultations.

Special thanks are extended to Brent Schaur and the A.V. staff for the production of the graphic work that appears in this thesis. 
TABLE OF CONTENTS

PAGE

ACKNOWLEDGEMENTS

LIST OF TABLES

LIST OF FIGURES

INTRODUCTION

MATERIALS AND METHODS . . . . . . . . . . . . . 7

Bacterial Strains and Bacteriophage . . . . . . . 7

Media . . . . . . . . . . . . . . . 8

Growth Conditions . . . . . . . . . . . . 9

Isolation of Mutants . . . . . . . . . . . . 9

Nitrosoguanidine (NTG) Mutagenesis . . . . . . 10

Verification of Strain Purity . . . . . . . . 10

Minimum Inhibitory Concentrations (MIC) . . . . . • 11

Aerobic and Anaerobic Growth Yields . . . . . . . 11

Conjugation Techniques . . . . . . . . . . . 11

Transduction Procedures . . . . . . . . . . 14

Adenosine Triphosphate (ATP) Determinations . . . . 15

Thin Layer Electrophoresis . . . . . . . . 15

RESULTS $\quad$. . . . . . . . . . . . . 17

DISCUSSION $\quad$. . . . . . . . . . . . . . 42

LIST OF REFERENCES . . . . . . . . . . . . . . . 46 


\section{LIST OF TABLES}

\section{TABLE}

I. The Pattern of Carbon Source Utilization of Strains PS21, PS25 and AN120 • • • • • • • • • . 25

II. The Gradient of Transmission of the Arsenite Sensitivity Marker from Strain CSH61 to Strain 


\section{LIST OF FIGURES}

FIGURE

PAGE

1. The Minimum Inhibitory Concentration of Arsenite for Strains PS21, PS24, and PS25 . . . . . . . . . 18

2. The Minimum Inhibitory Concentration of Arsenate for Strains PS21, PS24, and PS25 . . . . . . . . . 20

3. Thin Layer Electropherogram Comparing the Oxidation of Arsenite to Arsenate by Strains PS25 and YE56 . . . 23.

4. The Final Growth Yields on Limiting Concentrations of Glucose for Strains PS21, PS25, and AN120 . • . . . 27

5. The Minimum Inhibitory Concentration of Streptomycin for Strains PS21 and PS25 . . . . . . . . . . . 29

6. The Time of Entry of the Asi ${ }^{S}$ Marker from the Hfr Strain CSH64 to Strain PS27 . . . . . . . . . . 33

7. The Minimum Inhibitory Concentration of Neomycin for Strains PS21 and PS25.. . . . . . . . . . . 37

8. Cellular ATP Levels in Strains PS21 and PS25 After Exposure to Arsenite . . . . . . . . . . . 40 


\section{INTRODUCTION}

The most notable biological effect of arsenic is its toxicity. The ability of arsenic-containing compounds to kill organisms has been exploited in various fashions throughout history. The death of Napoleon Bonaparte has been attributed to arsenic poisoning (1). Recently, hair samples taken from Napoleon after his death have been analyzed for arsenic content by neutron-activation. The levels found were 20-fold higher than normal (2). Although the exact cause of Napoleor's death is still controversial the possibility exists that he was deliberately poisoned by his attending physicians. The ability of arsenic to act as a chemotheraputic agent against pathogenic organisms has been exploited since the 19th century. Ehrlich's "magic bullet", Salvarsan (arsphenamine), and other arsenicals were used to kill the organisms responsible for syphillis and trypanosomiasis (3). Historically, the poisonous properties of arsenic have also been used in agriculture and industry. Paris Green, and other compounds containing arsenic have been employed widely as herbicides and pesticides since the late 1800's (4). The potential that arsenic has for harm and bene-

fit are well stated in the following 17 th century poem

I am an evil, poisonous smoke...

But when from evil I am freed, Through art and sleight of hand Then can I cure both man and beast, From dire disease ofttimes direct them; But prepare me correctly, and take great care That you faithfully keep watchful guard over me; For else I am poison, and poison remain 
That pierces the heart of many a one

$$
\text { Valentini, } 1694 \text { (5). }
$$

Arsenic-containing compounds have a wide distribution in air, water, and soil (6). The presence of arsenic in drinking water does not generally pose a threat to health, but there have been reports of chronic arsenic poisoning from drinking contaminated well water (7). Arsenic enters the environment principally as arsenic trioxide, a white odorless powder which is a byproduct from the smelting of non-ferrous metal ores such as copper and zinc (6). The continued use of arsenic in herbicides and pesticides, as well as its use in sheep dips to control ticks and fleas constitutes a significant health hazard (8). Exposure to arsenic-containing compounds has been associated with the development of several forms of cancer. An increase in lung cancer has been attributed to the inhalation of airborne arsenic trioxide by smelter workers (9). There is a strong correlation between arsenic therapy and bronchial carcinomas (10). Other forms of cancer associated with arsenic exposure include liver and skin cancer (11). Although no evidence exists that arsenic is a carcinogen in laboratory animals, it probably acts as a co-carcinogen. Evidence for this assertion stems from the demonstration that sodium arsenite was shown to decrease the ability of $\underline{E}$. coli cells to repair DNA following dammage by UV irradiation (12). A number of other disorders including hyperpigmentation, keratosis, and vascular abnormalities have been attributed to exposure to various forms of arsenic (11).

The metabolism and toxicity of arsenic depends on its chemical

form. A large number of organic compounds containing arsenic exist, 
but a discussion of them is beyond the scope of this thesis, which will focus exclusively on the effects of inorganic arsenic. Inorganic arsenic has three oxidation states, $-3,+3$, and +5 . Arsine, is a toxic gas, and is unstable in air (13). Its toxicity is not well understood, but may be explained by the tendency for arsine to be oxidized to arsenite.

The toxicity and metabolism of pentavalent arsenic, arsenate, has been thoroughly studied in eukaryotic and prokaryotic systems. It has been demonstrated that arsenate is an analogue of phosphate and can substitute for the latter in biochemical reactions (14). An important target of arsenate toxicity is substrate level phosphorylation. Substrate level phosphorylation involves the incorporation of inorganic phosphate into high energy organic phosphate bonds. The energy in this bond is conserved by transferring the high energy phosphate group to ADP forming ATP. An example of such a reaction is the oxidation of glyceraldehyde 3-phosphate to 3-phosphoglyceroyl phosphate ( 1,3 diphosphoglycerate) accompanied by the incorporation of inorganic phosphate into a high energy phosphate bond, which is subsequently transferred to ADP. When arsenate is present in cells, it substitutes for phosphate in this reaction forming 3-phosphoglyceroyl arsenate, a highly unstable compound that undergoes spontaneous decomposition (arsenolysis) to form arsenate and 3-phosphoglycerate. In this manner, arsenate uncouples the oxidation of glyceraldehyde 3-phosphate from the formation of ATP.

Arsenate presumably acts in a similar fashion as an uncoupler of oxidative phosphorylation. There are two principle steps that contri- 
bute to the production of ATP by this process. First, the oxidation of substrates by the electron transport system generates a transmembrane hydrogen ion gradient by extruding protons from the inside of a bacterial cell or mitochondrion (15). Second, the H+ ions move down their electrochemical potential gradient and pass through a complex, membrane bound enzyme, variously called the ATP synthetase or the adenesine triphosphatase (ATPase). As a result of the movement of protons through the ATPase, inorganic phosphate and ADP are combined to form ATP (16). In the presence of arsenate, substrates are oxidized and an electrochemical proton gradient is formed, but no ATP is generated by the ATPase $(5,17)$. It is likely that arsenate competes with phosphate in blocking ATP formation.

In order to exert its toxic effects, arsenate must enter the cell. Arsenate entry into $\underline{E}$. coli cells has been thoroughly studied. There are four phosphate uptake systems in $\underline{E}$. coli. Three of these systems do not readily discriminate between phosphate and arsenate, and transport both molecules into the cell (17). The primary uptakes system for inorganic phosphate (pit) is always present and functioning in wild type E. coli cells. The other two systems, the glycerol phosphate transport system ( $g l p T)$, and the hexose phosphate transport system (uhpT) are inducible and active only when $\underline{E}$. coli cells are grown on glycerol or hexose phosphate media, respectively. Mutants of E. coli that have lost a functional pit system for phosphate and arsenate transport, instead utilize the fourth, inducible, high affinity phosphate specific (pst) transport system that is better able to discriminate between phosphate and arsenate (18). Such mutants are resis- 
tant to arsenate except when grown under conditions where the glycerol or hexose phosphate transport systems are functioning and still able to transport arsenate into the cell (19).

Trivalent arsenic, arsenite, is the most toxic form of inorganic arsenic. The toxic effects of arsenite have generally been attributed to the ability of arsenite to combine with thiol (SH) groups on enzymes, thus inactivating them. An important target of arsenite toxicity is the oxidative decarboxylation of pyruvate to form acetyl CoA, an essential reaction by which carbohydrates are metabolized under aerobic conditions (5). A complex enzyme system named the pyruvate dehydrogenase complex carries out this reaction. During the reaction, an acetyl group from pyruvate is transferred to a thiol group on lipoic acid, a prosthetic group of lipoate acetyltransferase, which is a constituent of the enzyme complex. As diagrammed below, arsenite combines with the thiol groups of lipoic acid, preventing the reaction from occuring
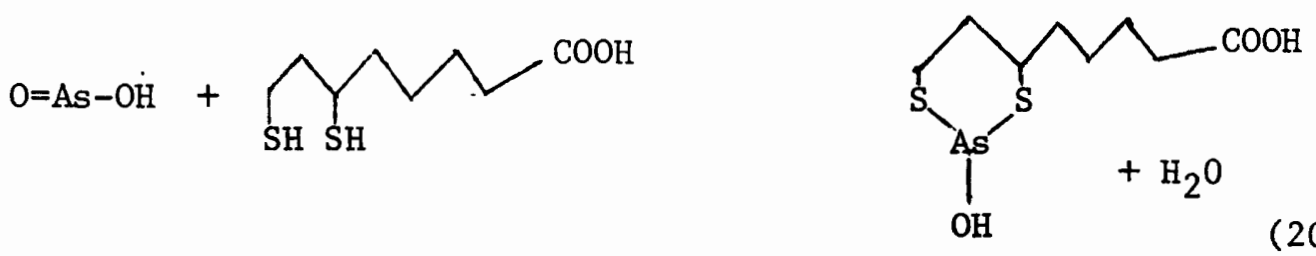

Arsenite has also been demonstrated to be an uncoupler of oxidative phosphorylation in mitochondria (5). The reason for this may be that arsenite increases the rate of ATP breakdown to ADP and inorganic phosphate, possibly by stimulating the ATP synthetase to hydrolyze, rather than synthesize ATP. This phenomenon might explain the previously mentioned inhibition of DNA repair by arsenite in E. coli 
cells. Arsenite lowered ATP levels in both the UV irradiated and unirradiated cells (12). It had previously been demonstrated that DNA repair is enhanced by ATP in E. coli cells (21).

There is no information at the present time concerning the transport of arsenite into $\underline{E}$. coli cells. It is not known if arsenite is even taken up into E. $\underline{\text { coli }}$ cells at all. Some bacteria are naturally resistant to arsenite but the mechanisms involved have not been completely characterized. Some bacteria detoxify arsenite by oxidizing it to arsenate (22). Other strains carry extrachromosomal, self-replicating DNA elements called plasmids, which can confer resistance to both arsenate and arsenite (23). The plasmid genes involved with arsenite and arsenate resistance in $\underline{E}$. coli are separate, indicating different resistance mechanisms (23). The genes involved in non-plasmid, chromosomally determined arsenite resistance have not been characterized in any bacterial organism, including E. coli.

The purposes of this thesis were to gain an insight into the mechanism of arsenite resistance in Escherichia coli, and by comparing wild type and resistance mutant strains, to obtain information concerning the primary target site for arsenite toxicity in E. coli cells. 
MATERIALS AND METHODS

Bacterial Strains and Bacteriophage

The following is a list of the bacterial strains and bacteriophage used for these studies.

Escherichia coli

\begin{tabular}{|c|c|c|c|}
\hline Strain & $\underline{\text { Sex }}$ & Relevant Genetic Markers & Source \\
\hline PS21 & $\mathrm{F}^{-}$ & $\frac{\text { leu }}{\text { arg }} \frac{\text { rps } 1}{\text { rpp }} \frac{\text { his }}{\text { ilva }} \frac{\text { metA }}{\text { methi }}$ & J.W. Myers. \\
\hline PS 24 & $\mathrm{~F}^{-}$ & $\begin{array}{l}\text { Asa }{ }^{r} \text { other markers as } \\
\text { in PS } 21\end{array}$ & $\begin{array}{l}\text { Spontaneous Asi }{ }^{\mathrm{r}} \\
\text { mutant of PS } 21 \\
\text { selected on } 40 \mathrm{mM} \\
\text { arsenate }\end{array}$ \\
\hline PS25 & $\mathrm{F}^{-}$ & $\begin{array}{l}\text { Asi } i^{r} \text { other markers as } \\
\text { in PS } 21\end{array}$ & $\begin{array}{l}\text { Spontaneous Asir } \\
\text { mutant of PS } 21 \\
\text { selected on } 7 \mathrm{mM} \\
\text { arsenite }\end{array}$ \\
\hline PS27 & $\mathrm{F}^{-}$ & $\begin{array}{l}\mathrm{Nal}^{\mathrm{r}} \text { other markers as } \\
\text { in PS } 21\end{array}$ & $\begin{array}{l}\text { Spontaneous } \mathrm{Nal}^{\mathrm{r}} \\
\text { mutant of PS } 25 \\
\text { selected on } 50 \mu \mathrm{g} / \mathrm{ml}\end{array}$ \\
\hline & & & nalidixic acid \\
\hline PS 28 & $\mathrm{~F}^{-}$ & $\begin{array}{l}\mathrm{BgI}^{+} \text {other markers as } \\
\text { in PS } 21\end{array}$ & $\begin{array}{l}\text { Spontaneous } \mathrm{Bg}^{+} \\
\text {mutant of PS } 25 \\
\text { selected in the } \\
\text { presence of } 0.2 \% \\
\text { salicin }\end{array}$ \\
\hline CSH61 & $\mathrm{Hfr}$ & thi $s t^{S}$ & $\begin{array}{l}\text { Cold Spring Harbor } \\
\text { Laboratory }(24)\end{array}$ \\
\hline CSH64 & $\operatorname{Hfr}$ & thi $\operatorname{str}^{S}$ & $\begin{array}{l}\text { Cold Spring Harbor } \\
\text { Laboratory }(24)\end{array}$ \\
\hline AN346 & $\mathrm{F}^{-}$ & $\mathrm{Unc}^{+}$ & $\begin{array}{l}\text { E. coli Genetic } \\
\text { Stock Center (ECGSC) } \\
\text { \#6307 }\end{array}$ \\
\hline
\end{tabular}




\begin{tabular}{|c|c|c|c|}
\hline Strain & Sex & Relevant Genetic Markers & Source \\
\hline AN 120 & $\mathrm{~F}^{-}$ & uncA 401 & ECGSC 非 5100 \\
\hline AN719 & $\mathrm{F}^{-}$ & uncB 402 & ECGSC 非6309 \\
\hline AN781 & $\mathrm{F}^{-}$ & uncC 424 & ECGSC 非6310 \\
\hline AN817 & $\mathrm{F}^{-}$ & uncD 409 & ECGSC 非6311 \\
\hline AN9 36 & $\mathrm{~F}^{-}$ & uncE 429 & ECGSC 非6312 \\
\hline AN 1419 & $\mathrm{~F}^{-}$ & uncF 469 & ECGSC 非6313 \\
\hline \multicolumn{4}{|c|}{ Alcaligenes faecalis } \\
\hline YE56 & $\mathrm{F}^{-}$ & Asi $i^{r}$ & M.L. Taylor \\
\hline
\end{tabular}

\section{Bacteriophage}

The bacteriophage used in this work was P1V.

Media

Two media were used for the physiological studies. One was a modification of Neidhart's minimal medium for Enterobacteria (N medium) (25). The calcium chloride concentration was increased to $5 \times 10^{-3} \mathrm{M}$, the potassium phosphate concentration was $1.00 \mathrm{mM}$, and the sodium bicarbonate was eliminated. The medium of Davis and Mingiola (Davis medium), was used as the other medium (26). For both media, unless otherwise stated, glucose $(0.5 \%)$ was used as the carbon source, and growth factors were added to a final concentration of $0.05 \%$, except adenine hydrochloride $(0.25 \%)$, and thiamine hydrochloride $(0.001 \%)$. Other sugars used as indicated, were added to a final concentration of $0.2 \%$. Media for conjugation and transduction studies were LB medium, Luria broth, and $H$ medium. These media were prepared as described by Miller (24). Soft agar tubes were prepared with $0.8 \%$ 
Difco agar and used at 45C. Fifteen grams per liter Difco agar was added to liquid media for use in plate cultures.

Arsenate was added as the disodium salt, and arsenite was added as the sodium salt. Arsenite was neutralized with 0.8 equivalents of HCL immediately prior to use.

\section{Growth Conditions}

Unless otherwise stated, liquid cultures were grown in $10 \mathrm{ml}$ volumes in $125 \mathrm{ml}$ erlenmeyer flasks, fitted with a side arm for turbidity measurements (klett flasks). Cultures were grown at $37 \mathrm{C}$ with shaking at $200 \mathrm{rpm}$ in a Model G-25 NBS gyrotory shaker. A Klett-Summerson photoelectric colorimeter with a $\$ 66$ filter was used for measuring turbidity. Plate cultures were incubated at $37 \mathrm{C}$ in a model 4 Thelco incubator. For the construction of growth curves, Klett readings were recorded, and plotted against time. Viable counts were determined by plating $0.1 \mathrm{ml}$ aliquots from serial dilutions of cell suspensions on LB medium using the soft agar overlay technique.

\section{Isolation of Mutants}

Spontaneously occuring arsenate and arsenite resistant mutants of strain PS21 were selected as follows: Exponentially growing cells in $\mathrm{N}$ medium were harvested by centrifugation at room temperature and resuspended in $1 / 10$ volume of the same medium. At that point, an aliquot was removed for viable counting. Varying amounts of the concentrated suspension were plated on the above medium containing $7 \mathrm{mM}$ arsenite, $10 \mathrm{mM}$ arsenite, $40 \mathrm{mM}$ arsenate, or both $40 \mathrm{mM}$ arsenate and $7 \mathrm{mM}$ 
arsenite, using the soft agar overlay technique. Resistant cells produced visible colonies after 3-5 days of incubation.

\section{Nitrosoguanidine (NTG) Mutagenesis}

Cells of strain PS21 were grown in $10 \mathrm{ml}$ of $\mathrm{LB}$ medium to a klett reading of 30 , harvested by centrifugation, washed twice with $0.1 \mathrm{M}$ sodium citrate buffer $\mathrm{pH} 5.5$, and resuspended in the original volume of the same sodium citrate buffer. One milligram of NTG was added and the cells were placed in a $37 \mathrm{C}$ water bath for 30 minutes, without shaking. At the end of that time, $4.0 \mathrm{ml}$ of cells were centrifuged, washed with an equal volume of $0.1 \mathrm{M}$ potassium phosphate buffer $\mathrm{pH} 7.0$, and resuspended in 10m1 of LB medium. The cells were incubated for 4 hours, harvested by centrifugation, and resuspended in $10 \mathrm{ml}$ of $\mathrm{N}$ medium. An aliquot was removed at that time for a viable count. One milliliter samples $\left(8 \times 10^{8} \mathrm{cells} / \mathrm{ml}\right)$ were plated on $\mathrm{N}$ medium containing $10 \mathrm{mM}$ arsenite, or both $40 \mathrm{mM}$ arsenate and $7 \mathrm{mM}$ arsenite, using the soft agar overlay technique.

\section{Verification of Strain Purity}

Arsenate and arsenite resistant colonies were purified by successive streakings on arsenate- or arsenite-containing plates, respectively. To maintain uniform colony morphology, it was necessary that arsenite resistant strains be restreaked every three days onto the appropriate medium. The parental strain and the arsenate resistant strains were restreaked every 5 days. 
Minimum Inhibitory Concentrations (MIC)

The minimum inhibitory concentration for arsenate, arsenite, streptomycin, and neomycin was established for the various strains in the following manner: Cells were grown to a klett reading of 50 in either $\mathrm{N}$ or Davis medium. Cell suspensions were diluted and approximately 100 cells, in 0.1 aliquots, were spread on plates containing increasing concentrations of inhibitor as well as control plates containing no inhibitor. Colonies were counted after 48 hours of incubation.

Aerobic and Anaerobic Growth Yields

Aerobic growth yields were determined in the following manner: Ten mililiters of Davis medium containing growth factors and different concentrations of glucose were innoculated with the appropriate strains. Turbidity was measured after 24 and 36 hours of incubation. Anaerobic cultures were prepared as follows: Sterile medium, as described for aerobic cultures, was aseptically injected into sterilized serum bottles that were sealed with rubber stoppers. The appropriate innocula were then injected into the bottles. The cultures were purged with $\mathrm{N}_{2}$ for three minutes and incubated without shaking. Turbidity was measured after 24 and 26 hours as previously described.

\section{Conjugation Techniques}

Many Hfr strains revert to $\mathrm{F}^{+}$strains which are characterized by low frequencies of recombination (27). The following test was 
carried out to obtain clones of the Hfr culture that had retained the characteristics of high frequency recombination. Forty isolated colonies of an Hfr strain were spotted on an LB plate in a grid pattern for easy location of strains. This "master" plate containing the presumptive Hfr strains was incubated overnight, and replica plated onto another LB plate according to the procedure outlined in Miller (24), and incubated 6-8 hours. In the meantime, an overnight liquid culture of a suitable recipient $\left(\mathrm{F}^{-}\right)$strain was washed twice with Davis medium containing no growth factors, and resuspended in one-fifth volume of the same medium. A $0.2 \mathrm{ml}$ aliquot of this concentrated suspension was spread on a Davis plate selective for recombinants which contained $200 \mu \mathrm{g} / \mathrm{ml}$ streptomycin to kill the Hfr strain. The plate also contained glucose, and all the growth factors required by the recipient strain, except one, thus preventing its growth also. The composition of this medium was such that only recombinants between the Hfr and the $\mathrm{F}^{-}$strain would be able to grow. The replica plate containing the presumptive Hfr strains was replica plated onto the selective medium containing the recipient cells. This selective plate and a control, consisting of an identical selective medium but no recipient cells, were incubated for 48 hours. After incubation, dense patches of growth indicating recombination mediated by an Hfr strain were distinguished from patches consisting of isolated colonies, which represented the revertant $\mathrm{F}^{+}$strains. An $\mathrm{Hfr}$ clone was streaked on an LB plate from the corresponding patch on the master plate. It was almost certain that isolated colonies from the streak plate were Hfr clones and were used for mating experiments. 
To find the approximate location of the gene determining arsenite resistance, a procedure similar to the one described by Miller was used (24). An Hfr strain was grown in LB medium supplemented with maltose, without shaking to avoid breakage of sex pili. Cells of the donor (CSH61) and recipient (PS25) strains were mixed in a male to female ratio of 1:20, and mating was allowed to occur for two hours at $37 \mathrm{C}$. After mating, dilutions were made in Davis medium containing no growth factors, and $10 \% \mathrm{LB}$. Aliquots, consisting of $0.1 \mathrm{ml}$ of cells, were plated on Davis media that selected for the production of recombinant clones corresponding to each of the auxotrophic markers of strain PS25. The plates contained $200 \mu \mathrm{g} / \mathrm{ml}$ streptomycin to select against the $\mathrm{Hfr}$ strain (CSH61). After 48 hours of incubation, 40 recombinant clones from each class of recombinant were tested for the inheritance of arsenite sensitivity from the male, by replica plating on selective media containing $10 \mathrm{mM}$ arsenite.

A time of ențry experiment was performed in a manner similar to the one described by Buock and Adelberg (28). A nalidixic acid resistant derivative of strain PS25, strain PS27, was used as the recipient. The nalidixic acid sensitive Hfr strain CSH64 was mated with PS27 at a final cell density of $2.5 \times 10^{9} \mathrm{cells} / \mathrm{ml}$ and a male to female ratio of $1: 3$, in a total volume of $1.2 \mathrm{ml}$. After 5 minutes at $37 \mathrm{C}$, the mating mixture was diluted 1:500 in 10\% LB in Davis medium containing no growth factors, and incubation was continued at 37C. Samples were removed every 5 minutes and transferred to soft agar tubes containing $50 \mu \mathrm{g} / \mathrm{ml}$ nalidixic acid, agitated and plated on Davis minimal agar containing glucose, nalidixic acid, and all the growth factors 
required by strain PS27 except one. The three markers selected for in this cross were $\mathrm{Arg}^{+}, \mathrm{Ile}^{+}$, and $\mathrm{Met}^{+}$. Care was taken not to disturb the mating pairs while removing the $0.1 \mathrm{ml}$ samples. After 48 hours of incubation, recombinant clones were counted and tested for the inheritance of the arsenite sensitivity marker as previously described.

\section{$\underline{\text { Transduction Procedures }}$}

To ensure a high titer lysate, free from any contaminating phage, the following procedure was used: A single PIV plaque from P1V(64) grown on strain PS28 was mixed with approximately $10^{5}$ PS28 cells in $0.5 \mathrm{ml}$ of $\mathrm{H}$ medium and incubated at $37 \mathrm{C}$. This suspension was allowed to lyse and an aliquot $(0.1 \mathrm{~m} 1)$ was diluted in $\mathrm{H}$ medium and titered by plating $0.1 \mathrm{ml}$ aliquots of the dilutions on a lawn of a susceptible strain. Phage from the first lysate were added to PS28 cells growing exponentially in $\dot{H}$ medium at a phage to cell ratio of $3.5: 1$. Turbidity was followed until it dropped rapidly to near zero. At that point, $\mathrm{CHCl}_{3}$ was added and cell debris removed by centrifugation. Each lysate was titered and kept sterile by the addition of $\mathrm{CHCl}_{3}$. Lysates were stored at $4 \mathrm{C}$, prior to use.

A transduction procedure similar to the one described by Cox and Downie (29) was used. An exponentially growing culture of strain CSH64 in Luria broth containing $2.5 \mathrm{mM} \mathrm{CaCl}_{2}$ was harvested by centrifugation and resuspended at a cell density of $10^{8} \mathrm{cells} / \mathrm{ml}$ in the same medium. An equal number of P1V(PS28) was added in a $0.1 \mathrm{ml}$ aliquot and the mixture was incubated at $37 \mathrm{C}$ for twenty minutes. The mixture was then centrifuged, washed twice in Davis medium containing no growth 
factors, and resuspended in $1 \mathrm{ml}$ of the same Davis minimal medium. Aliquots containing $0.1 \mathrm{ml}$ of this suspension were plated on Davis agar containing no growth factors and $0.2 \%$ salicin. Colonies representing transductants appeared after 48 hours and were purified by streaking on selective medium. Each transductant clone was tested for the inheritance of unselected markers (arsenite resistance and the uncoupled phenotype) by spreading loopfuls of a suspension of each clone on a Davis agar plate containing $4 \mathrm{mM}$ arsenite, and a similar plate where acetate replaced glucose as the carbon source without arsenite.

Adenosine Triphosphate (ATP) Determinations

Cellular ATP levels were determined essentially by the method of Kimmach et al (30). Samples containing $0.4 \mathrm{ml}$ of cells were transferred to $0.1 \mathrm{ml}$ of $3 \mathrm{~N} \mathrm{HClO}_{4}$ and allowed to remain on ice for $30 \mathrm{mi-}$ nutes. Assays were performed in a Beckman LS9000 liquid scintillation counter set on the coincidence mode. For each assay, $20 \mu 1$ samples of known or unknown amounts of ATP were added to $0.9 \mathrm{ml}$ of assay buffer. The reaction was started by adding $20 \mu 1$ of firefly lantern extract (Sigma) and counts per minute were recorded for 0.1 minutes. Known amounts of ATP were counted at regular intervals throughout each experiment to monitor the activity of the enzyme.

\section{Thin Layer Electrophoresis}

Arsenite, arsenate, and phosphate were separated by thin layer electrophoresis. Samples containing $0.8 \mu 1$ were spotted $5 \mathrm{~cm}$ from one edge of silica gel plates. The plates were sprayed with electrophor- 
esis buffer ( $0.1 \mathrm{M}$ sodium-acetate $\mathrm{pH} 8.1)$ and placed in a flat bed tap water cooled Desage-Heidelberg electrophoresis apparatus. Buffer tanks were filled with electrophoresis buffer. Electrophoresis wicks were prepared from Whatman 1 filter paper, washed several times in distilled water and soaked with electrophoresis buffer before bridging between the silica gels and the buffer tanks. Electrophoresis was carried out for 60 minutes at 400 volts using a constant voltage power source. Following electrophoresis, the plates were dried using a blow dryer. After drying, the plates were exposed to iodine vapors in a closed chamber for three minutes. Arsenite reacts with the $I_{2}$ to give a yellow spot. After removal from the chamber, the plates were left in air until the spots disappeared ( 30 minutes). The plates were then sprayed with a $1 \%$ solution of ammonium molybdate, blown dry at room temperature, sprayed with a solution of $1 \%$ stannous chlor-. ide in $25 \%$ concentrated $\mathrm{HCl}$ and finally blown dry. Arsenite (oxidized to arsenate by $I_{2}$ ), arsenate, and phosphate appeared as bright blue spots against a light blue background. 


\section{RESULTS}

Spontaneous arsenate resistant $\left(\mathrm{Asa}^{\mathrm{r}}\right)$ and arsenite resistant $\left(A s i^{r}\right)$ mutants of strain PS21 were readily obtained by plating cells on $\mathrm{N}$ or Davis medium containing $40 \mathrm{mM}$ arsenate or $7 \mathrm{mM}$ arsenite, respectively. The frequency of occurance of either mutant type was approximately $5 \times 10^{-8}$ in a population of sensitive PS21 cells. No spontaneous mutants resistant to $10 \mathrm{mM}$ arsenite were found after plating $10^{11}$ PS21 cells. Furthermore, no spontaneously occuring mutants, resistant to both $40 \mathrm{mM}$ arsenate and $7 \mathrm{mM}$ arsenite could be found in a population of $10^{10}$ PS21 cells. Attempts were made to obtain Asir mutants resistant to $10 \mathrm{mM}$ arsenite and mutants resistant to both $40 \mathrm{mM}$ arsenate and $7 \mathrm{mM}$ arsenite using NTG as a mutagen. Neither type of mutant was obtained after plating $5 \times 10^{9}$ PS 21 cells, treated with NTG, for each class of mutation.

The minimum inhibitory concentration. (MIC) for arsenate and arsenite was determined for the parental strain (PS21), an Asa mutant (PS24), and an Asi ${ }^{\mathrm{r}}$ mutant (PS25). The MIC for each inhibitor is defined as the concentration of inhibitor at which fifty percent of the cells plated survive to form colonies. As seen in Figures 1 and 2, the MIC for arsenite (Figure 1) of strains PS21, PS24, and PS25 is $3.0 \mathrm{mM}, 4.0 \mathrm{mM}$, and $7.4 \mathrm{mM}$ respectively. For arsenate (Figure 2), the MIC for the same strains is $10.5 \mathrm{mM}, 150 \mathrm{mM}$, and $10.5 \mathrm{mM}$ respectively. It is apparent from these results that mutation to Asar does not confer 
Figure 1. The Minimum Inhibitory Concentration of Arsenite for Strains PS21, PS24, and PS25.

Each point represents the average of three plates. 


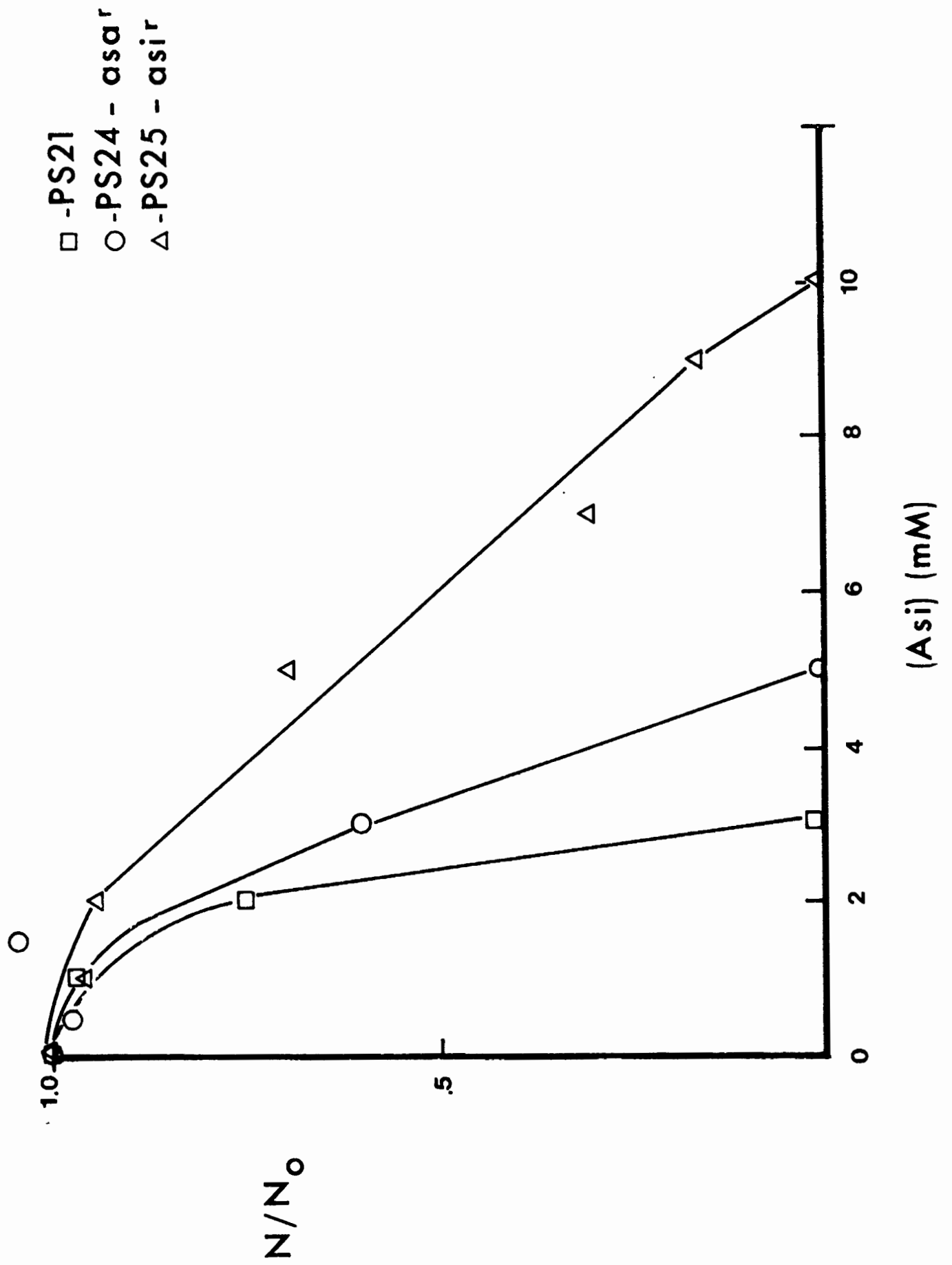


Figure 2. The Minimum Inhibitory Concentration of Arsenate for Strains PS21, PS24, and PS25.

Each point represents the average of three plates. 


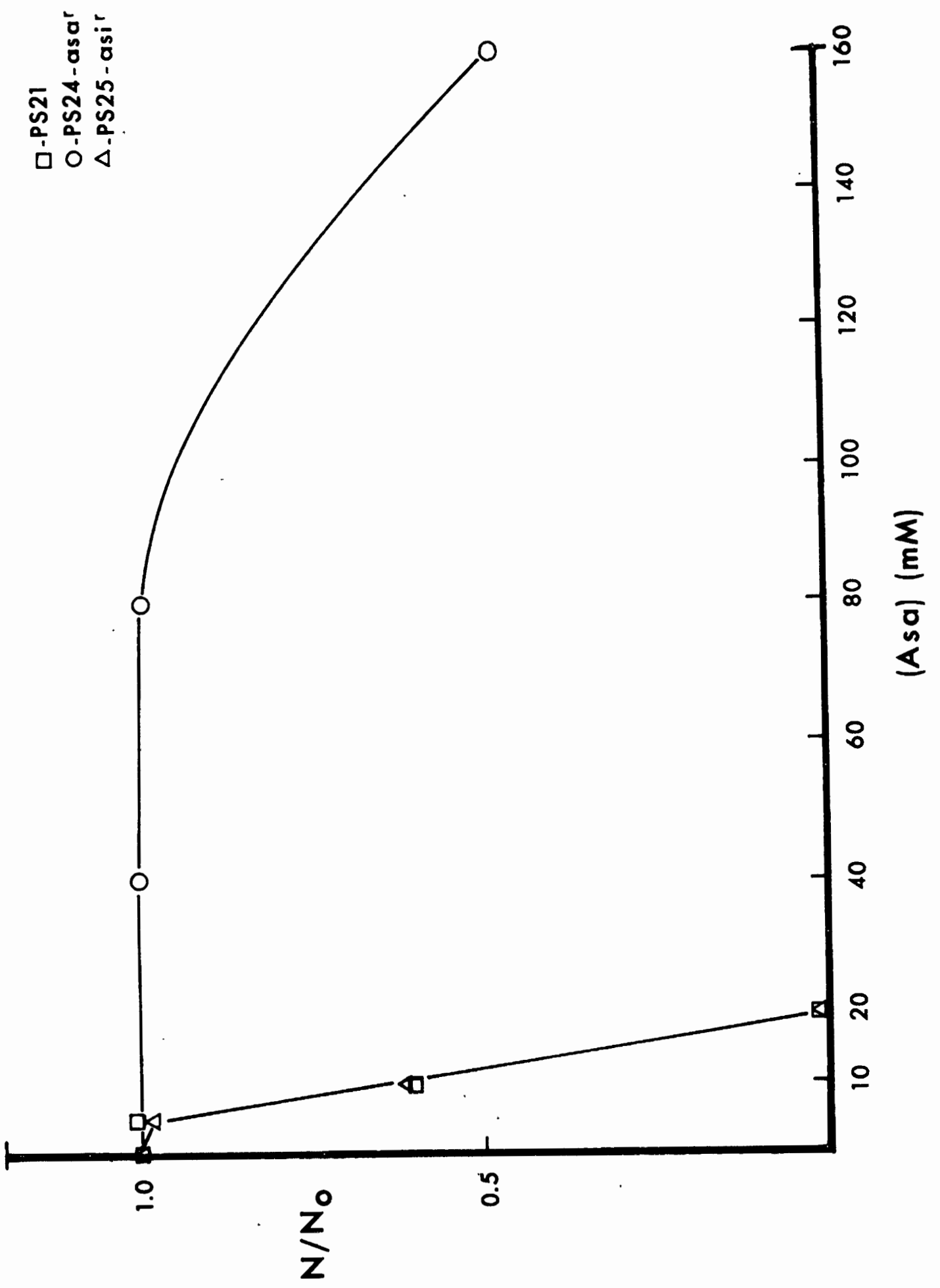


significant resistance to arsenite, and that the converse is also true, namely that spontaneous mutation to $\mathrm{Asi}^{\mathrm{r}}$ does not confer arsenate resistance. This information indicates that chromosomally determined arsenate and arsenite resistance in $\underline{E}$. coli are independent mutational events and thus genetically distinct.

It has been shown that certain strains of Alcaligenes faecalis detoxify arsenite by oxidizing it to arsenate (22). To determine if strain PS25 ( $\mathrm{Asi}^{\mathrm{r}}$ ) was able to oxidize arsenate, a liquid culture (N medium) was exposed to $10 \mathrm{mM}$ arsenite for 48 hours. The supernatant of that culture was subjected to thin layer electrophoresis to separate arsenate, arsenite, and phosphate. Figure 3 shows that strain PS25 is unable to oxidize arsenite to arsenate whereas the Asi ${ }^{\mathrm{r}}$ strain of Alcaligenes faecalis (YE56), grown in the same medium oxidizes all the arsenite to arsenate. This experiment rules out oxidation as a mechanism of arsenite resistance for strain PS25.

Early in these studies, slow growth and low growth yields were observed for PS25 when the cells were cultured in liquid LB medium is such that the predominant carbon sources are amino acids. A comparison of the amino acids utilized by strain PS25 and its parental strain PS21, revealed a difference in the pattern of amino acid utilization. Strain PS21 was able to grow on alanine, asparagine, and proline as carbon sources whereas the arsenite resistant derivative (PS25) was not able to utilize these amino acids for carbon sourcss (Table I). It also can be seen from the table that other carbon sources, namely non-fermentable carbon sources such as acetate and succinate could be utilized by strain PS21, but not by strain PS25. This pattern of car- 
Figure 3. Thin Layer Electropherogram Comparing the 0xidation of Arsenite to Arsenate by Strains PS25 and YE56.

A reproduction of a typical eletropherogram. .

Lane \#

1. $10 \mathrm{mM}$ arsenate, arsenite, and phosphate in water

2. $10 \mathrm{mM}$ arsenite in $\mathrm{N}$ medium ( 48 hours)

3. Strain YE56 in $10 \mathrm{mM}$ arsenite ( $\mathrm{N}$ medium, 48 hours)

4. Strain PS25 in $10 \mathrm{mM}$ arsenite ( $\mathrm{N}$ medium, 48 hours) 

1
2
3
4

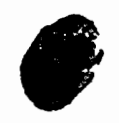

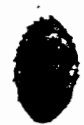

$-$

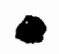

-

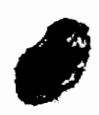

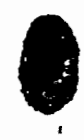

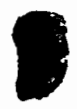


TABLE I

THE PATTERN OF CARBON SOURCE UTILIZATION OF STRAINS PS21, PS25, and AN120

Aerobic Growth

Carbon Source

glucose

L-proline

succinate

L-alanine

acetate

L-aspartate

\section{Bacterial Strains}

PS21

PS 25

AN 120

$+^{a}$

$+$

$+$

$+$

$+$

$+$

$+$

$+$

a Suspensions of each strain were spotted onto Davis medium containing each of the indicated carbon sources in the place of glucose. Growth was determined after 48 hours by the ability of the cells to form confluent patches. 
bon source utilization is identical to that of an uncoupled mutant, strain AN120 (Table I). The similarities in carbon source utilization between the uncoupled strain (AN120) and the Asi ${ }^{r}$ mutant of strain PS21 (PS25) led us to compare the properties of these strains further.

The aerobic and anaerobic growth yields on limiting concentrations of glucose were determined for strains PS21, PS25, and AN120. The results are shown in Figure 4. It can be seen that PS21 exhibits significantly higher growth yields than PS25 when grown aerobically, and is able to grow anaerobically on glucose. Strains PS25 and AN120 show similar growth yields aerobically, and both are unable to grow anaerobically on glucose. These data provide evidence that strain PS25 in addition to being Asir ${ }^{r}$ is uncoupled.

Another characteristic exhibited by uncoupled strains is an increased sensitivity to streptomycin (31). The parental strain from which the uncoupled mutant AN120 is derived (AN180), has an MIC for ștreptomycin of $512 \mu \mathrm{g} / \mathrm{ml}$. Strain AN120, however, has an MIC for streptomycin of $64 \mu \mathrm{g} / \mathrm{ml}$ (32). Strains PS21 and PS25 were compared for their sensitivities to streptomycin. As seen in Fgirue 5, strain PS25 is more sensitive to streptomycin than the parental type (PS21).

In order to determine if the uncoupled phenotype and the arsenite resistance of strain PS25 were the result of the same mutation, advantage was taken of the fact that uncoupled mutants are unable to grow on non-fermentable carbon sources such as acetate and succinate. Spontaneous revertants of strain PS25 were selected on Davis agar plates containing acetate or succinate as carbon sources: The fre- 
Figure 4. The Final Growth Yields on Limiting Concentrations of Glucose for Strains PS21, PS25, and AN120 Cultured Under Aerobic and Anaerobic Conditions.

Each point represents the average of two separate experiments. 


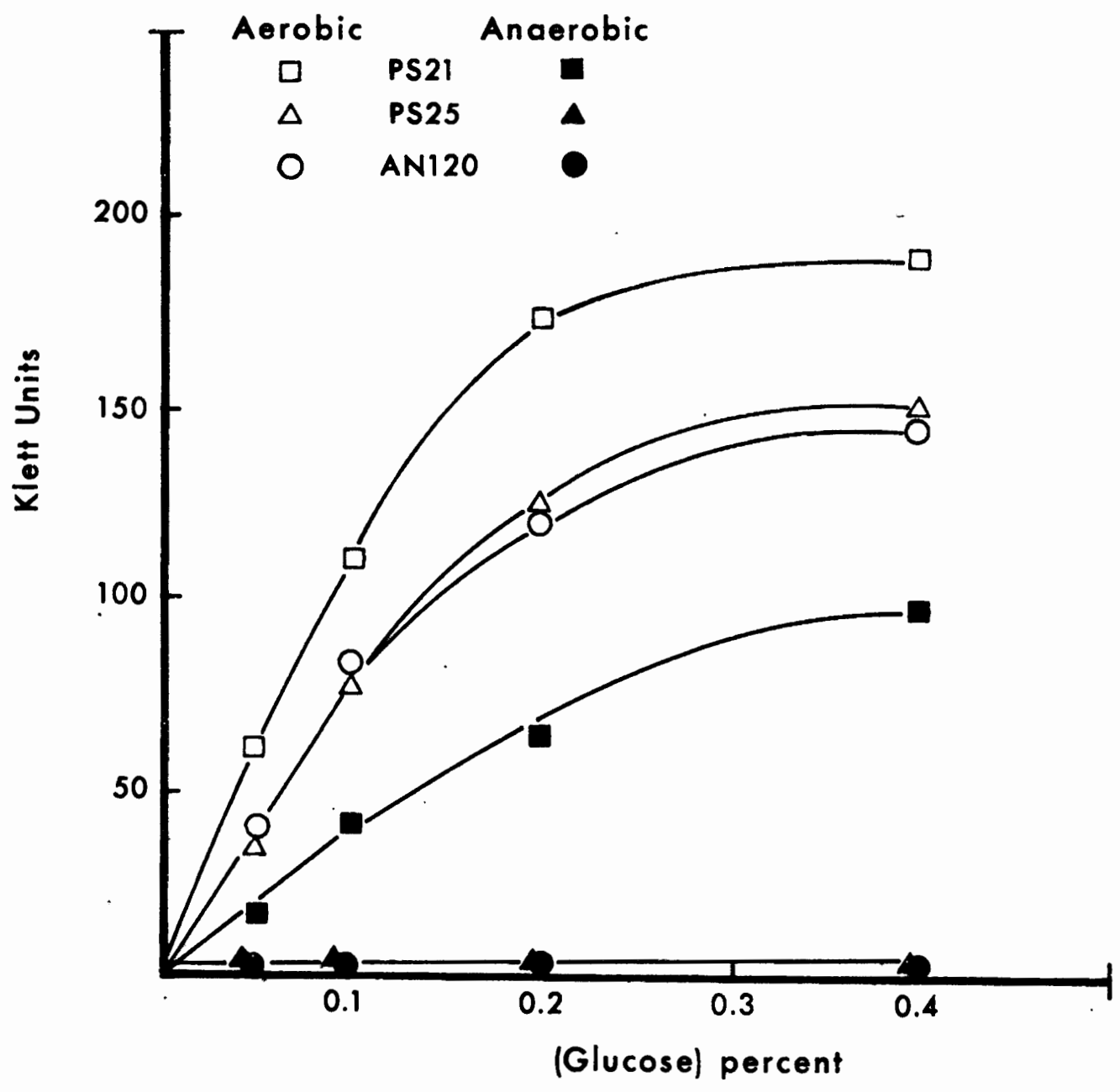


Figure 5. The Minimum Inhibitory Concentration of Streptomycin for Strains PS21 and PS25.

Each point represents the average of three plates. 


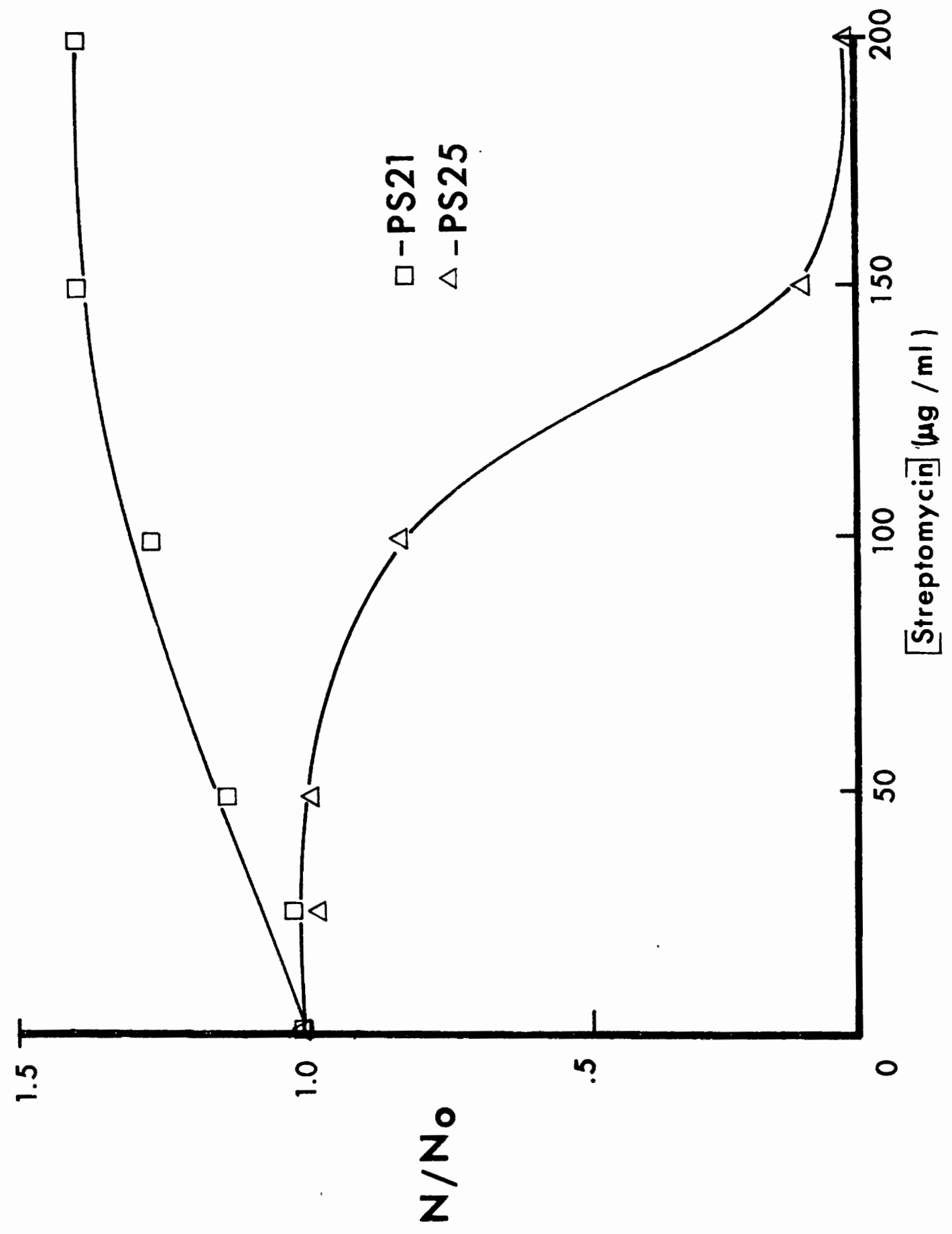


quency of spontaneous reversion from the inability to grow on succinate (Unc ${ }^{-}$) to the ability to utilize succinate $\left(\mathrm{Unc}^{+}\right.$) was approximately $5 \times 10^{-7}$. Among forty spontaneous revertants of strain PS25 that were able to grow on succinate, $40 \%$ exhibited the same sensitivity to arsenite as the parental strain (PS21). The remaining $60 \%$ demonstrated degrees of arsenite sensitivity intermediate between those of strains PS21 and PS25. The Asi ${ }^{r}$ spontaneous revertants had also regained their resistance to high levels of streptomycin and their ability to grow on other non-fermentable carbon sources such as proline. These data strongly indicate that arsenite resistance and the uncoupled phenotype in strain PS25 are the result of the same mutation.

The approximate location of the gene responsible for the arsenite resistance of strain PS25 was determined by a gradient of transmission experiment (Table II). The recombinant class showing the highest co-transfer frequency of arsenite sensitivity from the Hfr donor to the Asi ${ }^{\mathrm{r}}$ recipient (PS25) was the $\mathrm{Ile}^{+}$class. ${ }^{\mathrm{a}}$ This result indicates close linkage between the Asi ${ }^{\mathrm{r}}$ determinant and the ilvA 1ocus.

In order to determine if the above inference was correct, a time of entry experiment was performed. As seen in Figure 6, the times of entry of the known markers $\mathrm{Arg}^{+}, \mathrm{Ile}^{+}$, and $\mathrm{Met}^{+}$correspond to their known map positions, within experimental error. The data also show

The ilvA mutation in strain PS21 confers a nutritional requirement for isoleucine ( $\mathrm{Ile}^{-}$) but not valine ( $\mathrm{Val}^{-}$). The mutation maps in the ilv operon, but recombinants are given the phenotype designation $\mathrm{Ile}^{t}$. 
TABLE II

THE GRAIDENT OF TRANSMISSION OF THE ARSENITE SENSITIVITY MARKER FROM STRAIN CSH61 TO PS25

Selected Marker \% Asi ${ }^{\mathrm{S}}$ Recombinants

\begin{tabular}{|c|c|}
\hline $\operatorname{Ade}^{+} \operatorname{str}^{r}$ & 10 \\
\hline Leu $^{+} \operatorname{str}^{r}$ & 8 \\
\hline $\operatorname{Met}^{+} \operatorname{Str}^{r}$ & 85 \\
\hline $\mathrm{Ile}^{+^{\mathrm{a}}} \operatorname{Str}^{\mathrm{r}}$ & 95 \\
\hline $\operatorname{Arg}^{+} \operatorname{Str}^{r}$ & 83 \\
\hline $\mathrm{Phe}^{+} \mathrm{Str}^{\mathrm{r}}$ & 75 \\
\hline His $^{+}$'Str $^{r}$ & 66 \\
\hline $\operatorname{Tr}^{+} \operatorname{str}^{r}$ & 61 \\
\hline
\end{tabular}

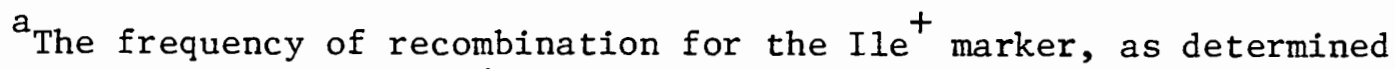
by the ratio of input males/ml to recombinants/ml was $6.1 \%$. 
Figure 6. The Time of Entry of the Asi $i^{5}$ Marker from the Hfr Strain CSH64 to Strain PS27

The frequency of recombination for the $\mathrm{Ile}^{+}$marker was $0.09 \%$. 


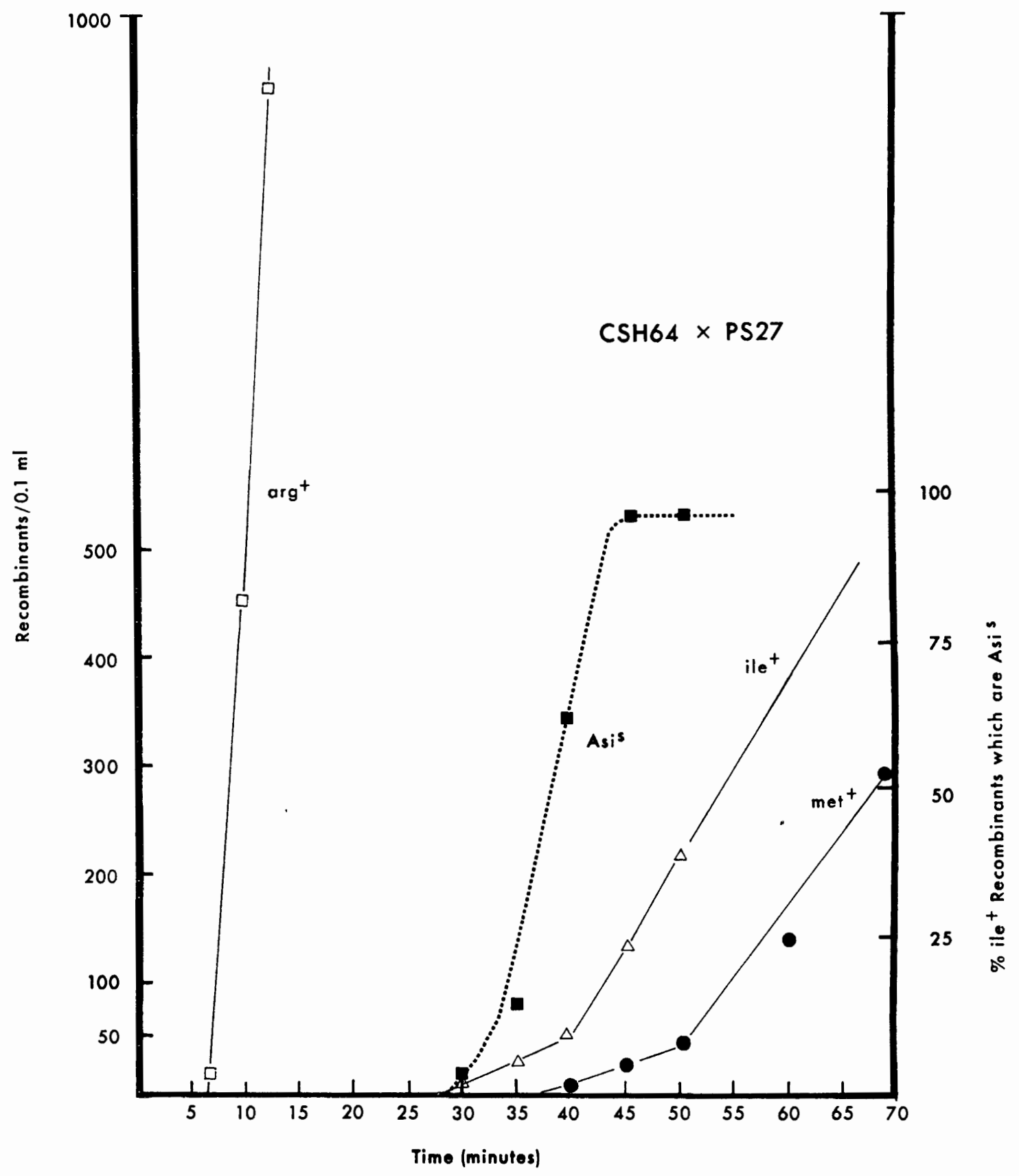


that the percentage of $\mathrm{Ile}^{+}$recombinants which are Asi ${ }^{\mathrm{s}}$ rapidly increases from $6 \%$ to $95 \%$ within the first fifteen minutes of $\mathrm{Ile}^{+}$entry. These data confirm the close linkage of the Asis marker and the ilvA locus.

Transduction mapping involves the transfer of DNA fragments, consisting of no more than 2 map units, from the donor to the recipient strain. This technique can be used to demonstrate direct linkage of two genes. A transduction experiment was performed for two purposes: (1) to determine if the Unc ${ }^{-}$phenotype of strain PS25 was the result of a mutation in the unc operon and (2) to see if the Unc' phenotype and the Asir phenotype of PS25 could be separated. It is known that mutations in the unc operon can be mapped by selecting for the $\mathrm{BgI}^{+}$marker (ability to utilize the beta-galactoside, salicin), which is within 1 map unit of the unc operon (33). Accordingly, a $\mathrm{BgI}^{+}$derivative of the $\mathrm{Unc}^{-} \mathrm{Asi}^{\mathrm{r}}$ mutant PS25 (PS28) was used as the donor. The recipient (strain $\mathrm{CSH} 64$ ) is $\mathrm{Unc}^{+}, \mathrm{Asi}^{\mathrm{S}}$, and $\mathrm{BgI}^{-}$. Selection was performed on salicin-containing agar. Thirty-one transductants, able to utilize salicin $\left(\mathrm{BgI}^{+}\right)$, were purified on salicincontaining agar. Each transductant was tested for the inheritance of the unselected markers $\mathrm{Asi}^{\Upsilon}$ and Unc ${ }^{-}$. Two classes of transductants were obtained. Class $\mathrm{I}$, representing $20 \%$ of the $\mathrm{BgI}^{+}$transductants (6 of 31) were $\mathrm{Unc}^{-}$and Asi ${ }^{r}$. The other class (class II), representing $80 \%$ of the transductants (25 of 31 ) was $\mathrm{Unc}^{+}$and $\mathrm{Asi}^{\mathrm{s}}$. In no case was the uncoupled phenotype and the arsenite resistance separated by transduction. These data show that (1) co-transduction of the uncoupled phenotype of strain PS25 occurs with $\mathrm{BgI}^{+}$indicating 
that the mutation confering the uncoupled phenotype is in or near the unc operon, and (2) that separation of arsenite resistance and the uncoupled phenotype was not observed, indicating that the two phenotypes were the result of the same mutation.

Since these experiments show that an Unc $^{-}$strain can also be Asi $^{r}$ (strain PS25), other known uncoupled strains were tested to determine if any of them were also resistant to arsenite. Mutants obtained from the E. coli Genetic Stock Center, representing 5 of the 8 known genes within the unc operon were compared with their parental strain to determine their arsenite sensitivity. Each strain was tested on Davis agar containing various concentrations of arsenite. All the strains tested, including the parental strain, exhibited the same sensitivity to arsenite as strain PS21.

To determine if strain PS25 was unique in being both $\mathrm{Asi}^{\mathrm{r}}$ and Unc $^{-}, 37$ spontaneous Asi ${ }^{\mathrm{r}}$ mutants of strain PS21 were selected and purified on Davis agar containing $7 \mathrm{mM}$ arsenite. Each mutant was tested for growth on succinate and for resistance to streptomycin $(200 \mu \mathrm{g} / \mathrm{ml})$. Approximately $15 \%$ (7 of 37 ) of these Asi ${ }^{\mathrm{x}}$ mutants exhibited the characteristics of an uncoupled mutant as defined by the above criteria: namely an inability to grow on succinate-containing agar and an increased sensitivity to streptomycin.

It is known that approximately $3 \%$ of all neomycin resistant $\left(\mathrm{Neo}^{\mathrm{r}}\right.$ ) mutants of $\underline{\mathrm{E}}$. coli are also uncoupled (34). To determine if strain PS25 was an example of a class of $\mathrm{NeO}^{\mathrm{r}} \mathrm{Unc}^{-}$mutants, an MIC for neomycin was determined for strains PS21 and PS25 (Figure 7). Strain PS25 exhibits a lowered rather than an increased resistance to 
Figure 7. The Minimum Inhibitory Concentration of Neomycin for Strains PS21 and PS25.

Each point represents the average of three plates. 


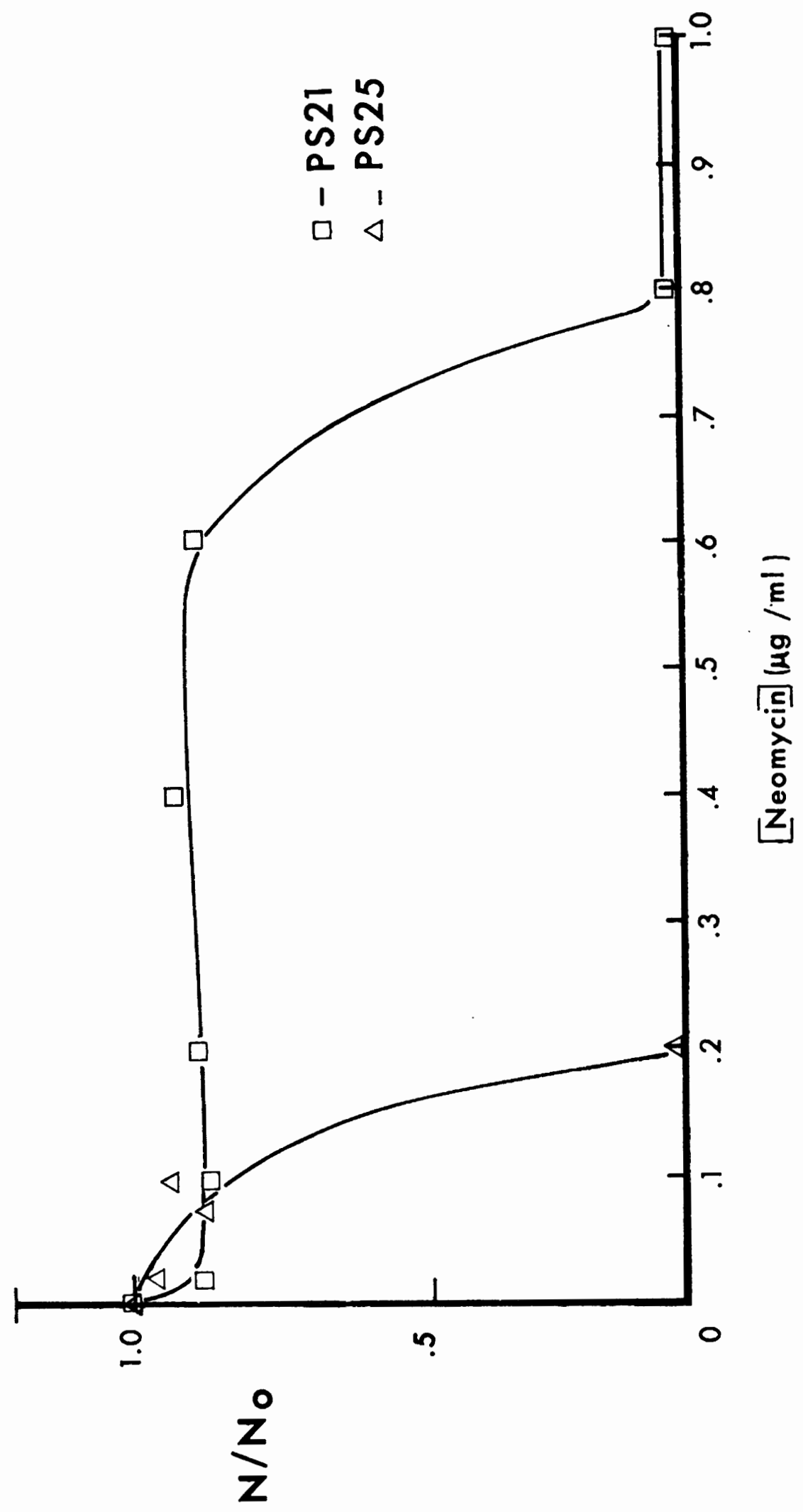


neomycin when compared to its parental strain (PS21). These results show that the $\mathrm{Asi}^{\mathrm{r}} \mathrm{Unc}^{-}$strain is not in the Neor ${ }^{\mathrm{r}} \mathrm{Unc}^{-}$class of mutants and represents a class of uncoupled mutants not previously described. Since a mutation leading to an uncoupled phenotype can also result in arsenite resistance, it was considered possible that arsenite might act directly on the wild type ATPase in E. coll, thus lowering ATP levels. Accordingly, cellular ATP levels were compared in strains PS21 and PS25. The data in Figure 8 demonstrates that arsenite rapidly lowers ATP levels in strain PS21 (Asis) but does not effect the levels of ATP in the Asi ${ }^{\mathrm{r}} \mathrm{Unc}^{-}$mutant strain (PS25).

In order to determine if the effect of arsenite on cells was bacteriocidal, the following experiment was performed: Arsenite ( $10 \mathrm{mM}$ final concentration) was added to an exponentially growing culture of PS21 in Davis medium. Samples were taken after 30,60 , and 120 minutes and viable counts determined. In spite of the fact that growth, as measured by turbidity, had completely stopped, there was no decrease in the viable counts of the samples throughout the two hour exposure period. Thus, any hypothesis concerning the mechanism of arsenite toxicity in $\underline{E}$. coli must take into account the fact that arsenite inhibition of growth is reversible. 
Figure 8. Cellular ATP Levels in Strains PS21 and PS25 After Exposure to Arsenite

Exponentially growing cells in Davis medium were exposed to $5 \mathrm{mM}$ arsenite. Samples were taken at the indicated intervals and ATP levels determined. 


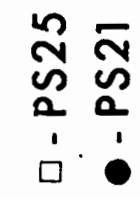

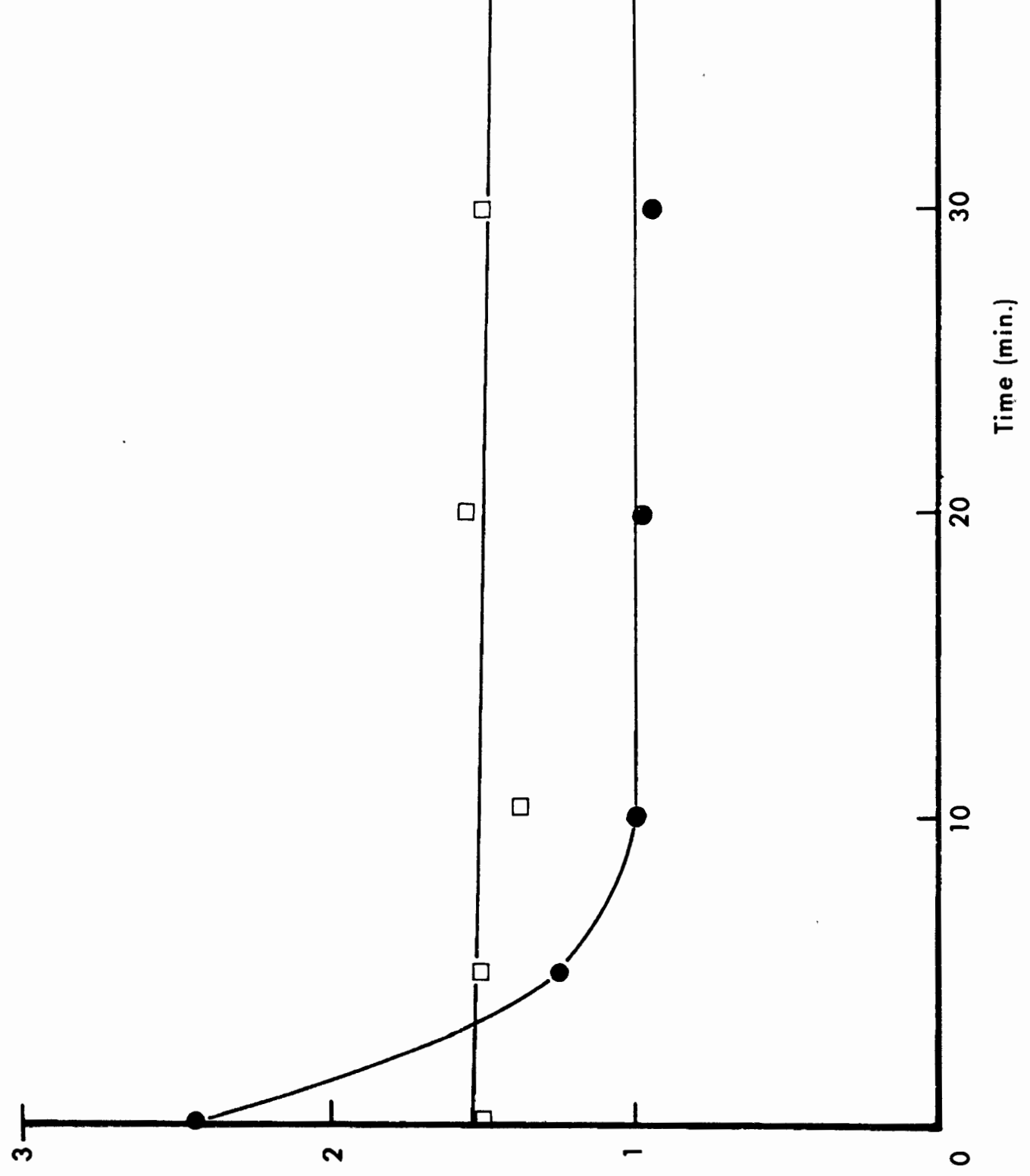

(ө/dwos jou!b!so ju//omu) $d L \forall$ 


\section{DISCUSSION}

A new class of uncoupled mutants of $\mathrm{E}$. coli have been discovered by selection for arsenite resistance. Recently, the uncoupled phenotype of the $\mathrm{Asi}^{\mathrm{r}} \mathrm{Unc}^{-}$strain PS25 was determined to be the result of a defective ATPase (35). This class of uncoupled mutants is clearly different from those uncoupled mutants obtained by selection for neomycin resistance. Neomycin selects for a specific class of uncoupled mutants that leak protons through their defective ATPase. As a result, these mutants have a lowered proton motive force (PMF) and are deficient in PMF-coupled transport systems, including the one for neomycin (36). The defective ATPase of strain PS25 apparently does not cause a lowered PMF since it demonstrates an increased rather than a lowered sensitivity to the aminoglycosides, neomycin and streptomycin (Figures 7 and 5). In this regard, PS25 is more like the uncA strain AN120, that does not have a leaky membrane. On the contrary, the rate of proton entry into cells of AN120 is reduced when compared to its parental strain (37). As a result, AN120 has an increased PMF which is manifested by its ability to transport streptomycin into the cell at a much higher rate than its parental strain, AN180 (32). As a consequence, AN120 is more sensitive to streptomycin than AN180. Strain PS25 also demonstrates an increased sensitivity to streptomycin which may be due to a similar increase in PMF. It should be emphasized, however, that strains AN120 and PS25 differ from each other because 
strain AN120 is arsenite sensitive (see Results).

The existence of these mutants that are distinct from any other class of uncoupled mutants, raises two questions: First, how could a mutational alteration in the ATPase increase the resistance of $\underline{E}$. coli cells to arsenite? Second, is the ATPase complex itself a primary target site for arsenite toxicity?

One explanation would be that arsenite stimulates the ATPase to break down ATP in wild type cells, and as a result of low ATP levels, growth would stop, even in the presence of glucose. Cells that have a defective ATPase would be unable to degrade ATP by this process and would thus be arsenite resistant. This hypothesis seems to be supported by the evidence presented in Figure 8 where arsenite lowers ATP levels in the wild type strain but not in the Asi ${ }^{r}$ Unc $^{-}$ mutant. If this hypothesis was entirely correct, however, any mutant lacking ATPase activity should be arsenite resistant. This has been shown not to be the case, as all the available unc strains, including those mutants which lack ATPase activity, revealed arsenite sensitivity comparable to wild type strains (see Results).

A defective ATPase may be directly involved in arsenite resistance in other ways. Arsenite may cause ions to leak from the inner membrane of $\underline{E}$. coli cells through the ATPase. This would cause a collapse of one or both components of the PMF. Evidence for this hypothesis comes from the observation that acute arsenite poisoning in humans leads to cardiac arrhythmias which are presumably due to ion imbalances across cardiac cell membranes (38). According to this 
hypothesis, the mutation in strain PS25 would prevent arsenite-induced ion leaks at the expense of depriving the cell of the ATP synthesizing activity of the ATPase. The observed drop in ATP levels due to arsenite (Figure 8) could be explained if ATP was being used to maintain the PMF collapsed by arsenite-induced ion leaks.

Another possibility is that arsenite enters $\underline{\text { E. }} \underline{\text { coli }}$ cells directly through the ATPase and exerts its inhibitory effects by covalently binding to intracellular enzymes (see Introduction). Although the data on reversibility do not support a hypothesis where covalent interactions exist (see Results), arsenite still might enter the cell through the ATPase. A mutation altering the structure of the ATPase could block arsenite entry or decrease its rate of entry, while eliminating ATPase synthetase activity.

Another possibility is that arsenite does not act directly on the ATPase, but that changes in the ATPase complex increase arsenite resistance in an indirect manner. If arsenite entry into cells were dependent on the low maintainance of the PMF at a sufficiently low level, then the presumed increase in PMF of strain PS25, as demonstrated by its heightened sensitivity to streptomycin, might make the cell more resistant to arsenite. In other words, arsenite entry would be an inverse function of the PMF. This conjecture is not consistent with the observation that strain AN120 is arsenite sensitive.

The use of arsenite to select uncoupled mutants has advantages over using neomycin, as the frequency of occurance is 5-fold higher. Additionally, since the strain of uncoupled mutant (PS25) is different from previously described mutants, there is a possibility that other classes of Asi ${ }^{\mathbf{r}}$ Unc $^{-}$mutants exist, which could be isolated 
and studied to gain more information concerning the nature of the ATPase complex.

In summary, approximately $15 \%$ of all Asi ${ }^{\mathrm{r}}$ mutants of strain PS21 also demonstrate an uncoupled phenotype. One such mutant analyzed in detail showed that the genes determining arsenite resistance and the uncoupled phenotype were the result of the same mutation and that the mutation mapped in or near the unc operon. 


\section{REFERENCES}

1. Murray, J.F. 1971. Napoleon- Of What Did He Die? South African Medical Journal. 45: 1005.

2. Forshufvud, S., H. Smith and A. Wassen. 1966. Arsenic Content Of Napoleon's Hair Probably Taken Immediately After His Death. Nature. 192: 103 .

3. Webb, S.L. 1966. Arsenicals. In Enzyme and Metabolic Inhibitors. New York Academic Press. p. 535.

4. Walsh, L.M. and D.R. Keeney. 1975. Behavior and Phytotoxicity of Inorganic Arsenicals in Soils. In Arsenical Pesticides, ACS Symposia Series 7. Ed. E.A. Woolson. American Chemical Society. p. 35 .

5. Weeks, M.E. and H. Leicester. 1968. In Discovery of the Elements. Journal of Chemical Education. p. 92.

6. National Research Council. 1977. Arsenic. Washington D.C., National Academy of Sciences. p. 332.

7. Goldbatt, E.S., A.S. van Denburg and R.A. Marsland. 1963. The Unusual and Widespread Occurance of Arsenic in We1l Waters of Lane County, Oregon. Oregon Dept. of Health. p. 24. 
8. Hill, A.B. and E.L. Faning. 1948. Studies of the Incidence of Cancer in a Factory Handling Inorganic Compounds of Arsenic. British Journal of Industrial Medicine. $\underline{5}: 1$.

9. Pinto, S.S. and B.M. Bennet. 1963. Effect of Arsenic Trioxide Exposure and Mortality. Archive of Environmental Health. 7: 583 .

10. Novry, H.S. and S.H. Martel. 1969. Asthma, Arsenic and Cancer. Journal of Allergy. 44:315.

11. Leonard, A. and R.R. Lauwerys. 1980. Carcinogenicity, Teratogenicity and Mutagenicity of Arsenic. Mutation Research. 75: 49

12. Fong, K., F. Lee and R. Bockrath. 1980. Effects of Sodium Arsenite on Single-Strand DNA Break Formation and PostReplication Repair in E. coli Following UV Irradation. Mutation Research. 70: 151 .

13. Braman, R.S. and C.G. Foreback. 1973. Methylated Forms of Arsenic in the Environment. Science. 182:1247.

14. Mahler, H.R. and E.H. Cordes. 1966. Biological Chemistry. N.Y., Harper and Row. p. 614.

15. Harold, F.M. 1979. Energy Coupling an Overview. In Microbiology. Ed. D. Schlessinger. Washington D.C., American Society for Microbiology. p. 42. 
16. Kagawa, Y., S. Nobuhito, H. Hajime and Y. Massasuke. 1979. Structure and Function of $\mathrm{H}^{+}$-ATPase. Journal of Bioenergetics and Biomembranes. 11: 39 .

17. Willsky, G. 1976. Inorganic Phosphate Transport and Alkaline Phosphatase Regulation in Escherichia coli. Tufts University, Ph. D. Dissertation.

21. Metzler, D.E. 1977. Biochemistry; The Chemical Reactions of Living Cells. N.Y., Academic Press. p. 688.

22. Phillips, S.E. and M.L. Taylor. 1976. Oxidation of Arsenite to Arsenate by Alcaligenes faecalis. Applied and Environmental Microbiology. 32:392.

23. Trezona, T., H. Taylor and M. Taylor. 1981. Differential Plasmid Genes for Arsenite and Arsenate Resistance in Escherichia coli. Abstract, Annual Meeting American Society for Microbiology. p. 314 .

24. Miller, J.H. 1972. Experiments in Molecular Genetics. N.Y., Cold Spring Harbor Laboratory. p. 466.

25. Neidhardt, F.C., P.L. Bloch and D.F. Smith. 1974. Culture Medium for Enterobacteria. J Bact. 119:736.

26. Davis, B.D. and E.S Mingioli. Mutants of Escherichia coli Requiring Methionine or Vitamin $B_{12}$ J. Bact. $60: 17$.

27. Hayes, W. 1968. The Genetics of Bacteria and their Viruses. 
N.Y., John Wiley and Sons. p. 656.

28. Buock, N. andiE.A. Adelberg. 1970. The Mechanisms of Action of Nalidixic Acid on Conjugating Bacteria. J. Bact. 102:688.

29. Cox, G.B. and J.A. Downie. 1979. Isolation and Characterization of Mutants of Escherichia coli $\mathrm{K}-12$ Affected in 0xidative Phosphorylation or Quinone Biosynthesis. Methods in Enzymology. Volume LVI, Part G. N.Y., Academic Press. p. 106.

30. Kimmich, G.A., J. Randles and J.S. Brand. 1976. Assay of Picomole Amounts of ATP,ADP, and AMP Using the luciferase Enzyme System. Analytical Biochemistry. $\underline{69}: 187$.

31. Thorbjarnardottir, S.H., Magnusdottir and G. Eggertson. 1978. Mutations Determining Generalized Resistance to Aminoglycoside Antibiotics in Escherichia coli. Molecular and General Genetics. $161: 89$.

32. Bryan, L.E. and H.M. Van Den E1zen. 1977. Effects of MembraneEnergy Mutations and Cations on Streptomycin and Genatamicin Accumulation by Bacteria. Antimicrobial Agents and Chemotherapy. 12: 163 .

33. Bachmann, B.J. and K. Brookslow. 1980. Linkage Map of Escherichia coli, Edition 6. Microbial Reviews. 44:1.

34. Kanner, B. and D. Gutnick. 1972. Use of Neomycin in the Isolation of Mutants Blocked in Energy Conservation in Escherichia 